\title{
The antiquity of hydrocephalus: the first full palaeo-neuropathological description
}

\author{
Raffaella Santi ${ }^{1}$ - Piera Rizzolo ${ }^{2} \cdot$ Michele Pietragalla $^{3}$ - Virginia Valentini ${ }^{2} \cdot$ Veronica Zelli $^{2} \cdot$ Francesco Maria Galassi $^{4}$. \\ Laura Ottini $^{2} \cdot$ Gabriella Nesi $^{1}$ (I)
}

Received: 12 June 2018 / Accepted: 8 November 2018 / Published online: 23 November 2018

(C) Springer-Verlag Italia S.r.l., part of Springer Nature 2018

\begin{abstract}
The Pathology Museum of the University of Florence houses a rich collection of anatomical specimens and over a hundred waxworks portraying pathological conditions occurring in the nineteenth century, when the museum was established. Clinical and autopsy findings of these cases can still be retrieved from the original museum catalogue, offering a rare opportunity for retrospective palaeo-pathological diagnostics. We present a historical case of severe hydrocephalus backed by modern-day anthropological, radiological and molecular analyses conducted on the skeleton of an 18-month-old male infant deceased in 1831. Luigi Calamai (1796-1851), a wax craftsman of La Specola workshop in Florence, was commissioned to create a life-sized wax model of the child's head, neck and upper thorax. This artwork allows us to appreciate the cranial and facial alterations determined by $30 \mathrm{lb}$ of cerebrospinal fluid (CSF) accumulated within the cerebral ventricular system. Based on the autopsy report, gross malformations of the neural tube, tumours and haemorrhage could be excluded. A molecular approach proved helpful in confirming sex. We present this case as the so-far most compelling case of hydrocephalus in palaeo-pathological research.
\end{abstract}

Keywords Hydrocephalus $\cdot$ Palaeoneurology $\cdot$ Pathology museum $\cdot$ Wax models $\cdot$ Palaeo-radiology $\cdot$ Ancient DNA

\section{Introduction}

The term "hydrocephalus" derives from the Greek words

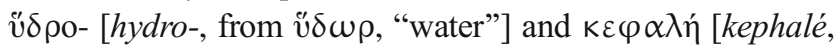
"head"], thus literally meaning "water on the brain".

Overall, the incidence of hydrocephalus is estimated at 1.1 cases per 1000 births and may be congenital or acquired [1]. Obstructions of the cerebrospinal fluid (henceforth, "CSF") pathway by congenital malformations of the neural tube (e.g.

Raffaella Santi and Piera Rizzolo contributed equally to the manuscript.

Gabriella Nesi

gabriella.nesi@unifi.it

1 Division of Pathological Anatomy, Department of Surgery and Translational Medicine, University of Florence, Largo Brambilla 3, 50134 Florence, Italy

2 Department of Molecular Medicine, Sapienza University of Rome, Rome, Italy

3 Radiology Section, University of Florence, Florence, Italy

4 Institute of Evolutionary Medicine, University of Zurich, Zurich, Switzerland
Arnold-Chiari malformation), tumours, infections or haemorrhage are the major causes. In rare instances, CSF overproduction and defective absorption may be responsible. In children, enlargement of the skull manifests prior to fusion of the cranial sutures. In older subjects, hydrocephalus is associated with expansion of the ventricles and increased intracranial pressure, with no modification in head circumference. Central nervous system infections, brain tumours, head trauma and intracranial haemorrhage (subarachnoid or intraparenchymal) can be responsible for acquired hydrocephalus. Untreated patients may suffer irreversible brain damage [2].

Physiopathologically, abnormal amount of CSF accumulating in the ventricles of the brain may cause increased intracranial pressure with progressive enlargement of the head and compression of the nervous tissue of the brain. This disease remained incurable until the twentieth century, when innovative advances in CSF valve technology were made [2].

From the perspective of the history of neurology, cases of hydrocephalus have been documented since antiquity, with references to hydrocephalus found in ancient Egyptian medical literature from $2500 \mathrm{BC}$ [3-5]. However, it is generally accepted that the Greek physician Hippocrates (c. 460-c. $370 \mathrm{BC}$ ) first described hydrocephalus as "water over the 
head" and the Persian doctor Rhazes (850-925) stated that the condition was caused by "water enclosed without exit, exiting upon death" [6]. The first clinical record of hydrocephalus and the relevant operative procedures appear in the medical encyclopaedia Al-Tasrif by the Arabian surgeon Abu al-Qasim alZahrawi (936-1013 AD), who wrote about evacuation of superficial intracranial fluid in hydrocephalic children [7]. In his chapter on neurosurgical diseases, he described infantile hydrocephalus as caused by mechanical compression. He stated:

"The skull of a newborn baby is often full of liquid, either because it has been excessively compressed by the expectant mother, or because of other unknown reasons. The volume of the skull then increases daily, so that the bones of the skull fail to close. In this case, three openings must be made in the middle of the skull, the liquid allowed to drain away, then the wound closed and the skull bandaged tightly" [3].

Over the following centuries, the famous physician Guy de Chauliac (c. 1300-1368) defined the condition as "aqua in capitibus puerorum" (water in children's heads) and Pietro d'Argellata (died 1423) "aquositas quae reperitur in capitibus puerorum" (the watery fluid which is found in children's heads). In 1543, Andreas Vesalius (1514-1564) was the first to define hydrocephalus as CSF accumulated within enlarged ventricles. This totally replaced the 2000 -year-old misinterpretation of hydrocephalus (i.e. extracranial or subdural fluid collection) clearing the way to further study on the circulation of CSF and its pathophysiology [3, 5]. Hydrocephalus remained a fatal condition until the twentieth century, when its management was eased with the development of shunts to divert CSF away from the cranial cavity [3].

From a palaeopathological perspective, several potential cases have been presented from different historical periods, quantified in 1991 to be about $n=30$ in total and ranging from $10,000 \mathrm{BC}$ to $1670 \mathrm{AD}[8,9]$. Another potential case of hydrocephalus dating back to $2800 \mathrm{BC}$ was subsequently described in the skull of a 13-year-old girl from the Burned City "Shahr-i Sokhta", Iran, on which evidence of cranial surgery could be detected [10]. This finding is considered highly significant, since the young patient survived the operation [11, 12].

Furthermore, a historically interesting case of non-severe hydrocephalus from the Italian Renaissance is represented by the skull of Don Filippino de' Medici (1577-1582), where a relevant correlation could be made between a somewhat realistic (yet not scientific) artistic representation, historical sources (including a sixteenth century autopsy report) and osteological and radiological evidence [13].

One main limitation perceived in palaeopathological research on hydrocephalus is the absence of clear diagnostic criteria [8], to which it can be added that often such cases are single instances, not always fully preserved.
Furthermore, lack of archival information of the studied specimens, which is a common issue in bioarchaeological contexts, prevents researchers from analysing vital details on the ancient patient's actual clinical manifestation $[14,15]$.

Here, we describe an extraordinary case of severe hydrocephalus in an 18-month-old child who died in 1831. His entire skeleton is preserved in the Pathology Museum of the University of Florence together with a life-sized wax reproduction of the head and upper thorax. Details of the clinical history are recorded in the museum catalogue. Founded in 1824, the Pathology Museum houses over a hundred waxworks and a vast number of anatomical preparations, including congenital malformations, genetic disorders and neoplasms. The original catalogue, in which specimens are listed and systematically described, together with the Registro delle Autopsie (autopsy register) containing 1469 post-mortem cases observed between 1839 and 1881, is held in the museum. Currently, visits to the Pathology Museum by medical undergraduates contribute to their scientific, historical and cultural education. These medical reports, unlike documentation from previous historical periods characterized by a certain descriptive vagueness due to the then not yet developed medical sciences, show an impressive degree of scientific detail and accuracy, which allows a far higher degree of source matching.

Training doctors was one of the reasons why the museum was established, and its history is closely linked to that of the first professorship of Pathological Anatomy in Italy (1840) at the University of Florence [16].

\section{Materials and methods}

In order to investigate this historical case of hydrocephalus in light of contemporary neuroscientific knowledge, we employed a diagnostic flowchart which included descriptions of the anatomical specimen and wax model, an outline of the clinical history, anthropometric methods, radiological findings and molecular testing. This virtuous combination of sources allows to best reconstruct the historical phenotype of ancient pathologies [17].

\section{Historical documentation, anatomical preparation and wax model}

The catalogue of the Pathology Museum was perused for clinical details and autopsy findings. The life-sized wax model accurately reproduced the child's head as it appears in the skeleton preserved in the museum collection.

\section{Anthropometric calculations}

Age at death was estimated on the basis of the degree of dental eruption and development $[18,19]$ and on post-cranial bone 
measurements without epiphyses [20]. Measurements of the bones were obtained using a sliding caliper (Martin type).

\section{Radiological examination}

Traditional antero-posterior (AP) X-ray projections of the skull, thorax, abdomen and upper and lower extremities were performed. Computed Tomography (CT) of the skull was also carried out, and CT images were taken using a bone reconstruction algorithm and Volume-Rendering Technique (VRT). $\mathrm{KVp}$ and $\mathrm{mAs}$ were not recorded in the study. This palaeoradiological analysis was implemented in order to better evaluate inner body changes brought about by the pathological status of this individual, with particular reference to the cranial level. Furthermore, radiological images were used to more correctly estimate the patient's age from epiphyseal fusion, ultimately comparing this evidence with the age reported in the written sources. Skeletal maturity was assessed following Greulich and Pyle's method [21].

\section{DNA extraction and genetic sex identification}

Approximately $300 \mathrm{mg}$ of bone tissue was removed from a rib fragment and finely ground with a Mikro-dismembrator S (Sartorius AG, Goettingen, Germany). DNA was extracted following a previously described protocol [22]. Quality and quantity of DNA were assessed with real-time PCR technology using Quantifiler Human DNA Quantification Kit (Applied Biosystems, Foster City, CA, USA) on ABI, a 7500 fast real-time PCR instrument, in accordance with the manufacturer's instructions.

For genetic sex determination, $\mathrm{X}$ and $\mathrm{Y}$ amelogenin loci, which differ in length, measuring 106 and 112 bp, respectively, were analysed using the primers and conditions formerly reported by Sullivan and co-authors [23].

\section{Results}

\section{Historical documentation, anatomical preparation and wax model}

This case of hydrocephalus is detailed in the museum catalogue alongside the description of the wax model (Fig. 1). The following is a translation of the original text:

catalogue no. 293-A wax model of a hydrocephalic head, increased in volume to just over 10 inches in diameter. This anatomical preparation, collected in 1831 , referred to an 18-month-old boy, hydrocephalic from birth and treated by Dr. Capecchi who donated this specimen to the hospital. The hydrocephalus was ventricular, the brain was extended like a membrane, containing 30

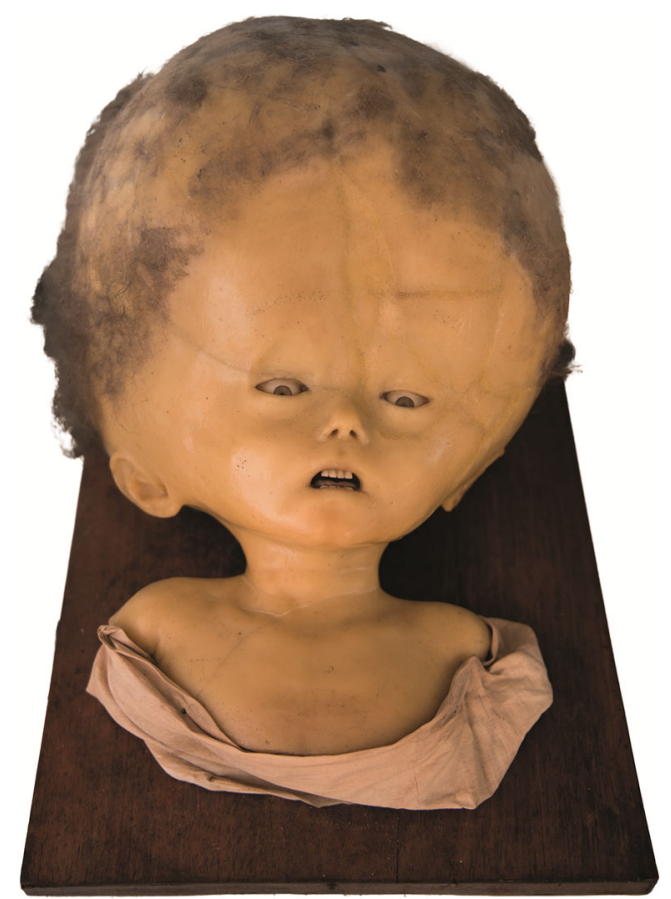

Fig. 1 Wax model depicting an 18-month-old infant with severe hydrocephalus (Luigi Calamai, 1831) housed at the Pathology Museum of the University of Florence. Courtesy of Roberta Ballestriero

pounds of fluid; the ratio between water and body weight being 17 to 30 . The waxwork closely resembled the huge deformed head. Measurements were taken at various points, giving the following: 33 ins in circumference at the os frontale, parietale and occipitale; 34 ins in circumference from the protuberantia mentalis through the os frontale to the spine, 23 ins from right to left auricle; 22 ins from nose to os occipitale.

On examining the infant skeleton, alteration of the external cranial vault with open sutures and thin bones, consequent to the conspicuous enlargement of the skull, was impressive. The skeleton was supported by a metal pole inserted into a wooden base (Fig. 2a,b). Copal varnish, commonly used to harden and preserve dried specimens, rendered the bones glossy in aspect.

The wax model by Luigi Calamai (1796-1851) depicts end-stage disease, possibly at the time of autopsy. The uncomely appearance of the child exemplifies the scientific aim of this remarkable replica.

\section{Anthropometrics}

The individual only has the maxilla from which the four deciduous incisors (central and lateral, bilaterally) erupted. Within the alveolar process of the maxillary bone, the developing gems of the canines and first and second deciduous molars can be seen. Moreover, the bilateral presence of developing crowns of the permanent superior first molars can be highlighted on the occlusal plane. 


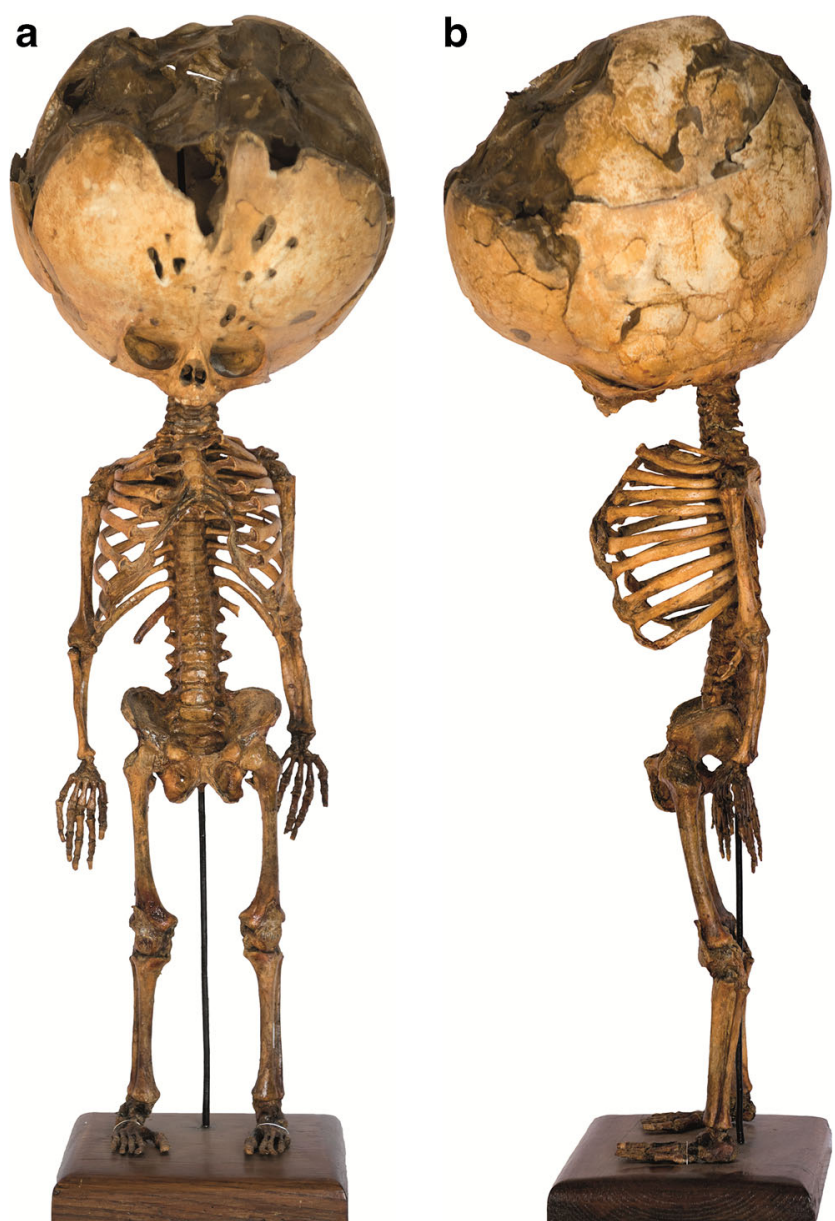

Fig. 2 The entire skeleton of the child suffering from hydrocephalus (Pathology Museum of the University of Florence). a Frontal view. b Lateral view. Courtesy of Roberta Ballestriero

Ubelaker's method $\rightarrow 12$ months \pm 4 months Al Qahtani's method $\rightarrow 10.5$ months \pm 3 months

The following measures were obtained, underling a substantial symmetry of both upper and lower limbs:

Humerus: left $=109 \mathrm{~mm}$; right $=108 \mathrm{~mm}$

Radius: left $=77 \mathrm{~mm}$; right $=78 \mathrm{~mm}$

Ulna: left $=94 \mathrm{~mm}$; right $=93 \mathrm{~mm}$

Femur: left $=120 \mathrm{~mm}$; right $=120 \mathrm{~mm}$

Tibia: left $=105 \mathrm{~mm}$; right $=105 \mathrm{~mm}$

Fibula: left $=101 \mathrm{~mm}$; right $=101 \mathrm{~mm}$

Maresh's method $\rightarrow$ 6-12 months, average $=9$ months.

\section{Palaeo-radiological analysis}

A total of fifteen radiographs and a skull-brain CT were acquired. The skull, upper and lower limbs and pelvis were scanned with AP X-ray projections (Fig. 3a-d). Imaging demonstrated marked enlargement of the skull vault with mild prevalence of the transverse diameter caused by increased intracranial pressure. The bregmatic fontanelle was pathologically open for the age of the child (Fig. 3a). Radiographs of the lower limbs showed lateral subluxation of the right tibiotalar joint, subtalar dislocation and slight medial deviation of the first metatarsal bone. There was evidence of asphericity of the femural head and coxa vara bilaterally (Fig. 3b,c). Mild convex right thoracic scoliosis was evident (Fig. 3d). There were no other skeletal alterations of the thorax, upper and lower limbs or pelvis.

CT scans obtained with bone Hounsfield Unit (HU) window showed marked enlargement of the posterior and middle cranial fossae, with thinning of the vault and skull bones, most likely caused by compression of the cerebral cortex from abnormally elevated intracranial pressure (Fig. 4a,b). VRT 3D reconstruction confirmed the above-mentioned skull findings and demonstrated the persistence of the right mastoid fontanelle, normally closed at 18 months (Fig. 4c). Signs of skull fractures were absent.

Besides this consideration of the fontanelles, since the skull is severely affected by the pathological process, it cannot be appropriately used for age-estimation purposes. Moreover, the mandibular bone is missing; thus, the mandibular symphysis, which fuses during the first year of extrauterine life, cannot be evaluated. The epyphyses of the long bones are all open, which, however, simply indicates that the individual was not an adolescent. Through the radiograph of the individual's hands, the Greulich-Pyle method gives an interval between 9 and 12 months (average 10.5 months).

\section{Ancient DNA amplification and genetic sex identification}

For each sample, the cycle number of amplification was compared with a standard curve generated from a series of DNA standards, translating the cycle number into a DNA concentration (Fig. 5). An internal PCR control (ICP) system template was added to exclude any false results due to the presence of PCR inhibitors and chemical or instrumental failure. A good ICP amplification plot was obtained, indicating the absence of amplification inhibitors (Fig. 5). Comparing the amplification curve of rib fragment DNA with the standard curve resulted in a DNA concentration of $0.7 \mathrm{ng} / \mu \mathrm{l}$. Molecular analysis proved that the rib fragment belonged to a male (Fig. 6).

\section{Discussion}

The current case, a most severe phenotype of hydrocephalus, was considered worthy of preservation both as an anatomical preparation and wax model. Perusal of the documentary sources provided relevant information on the original context 
Fig. 3 a Rx A-P projection of the skull. Hydrocephalus caused enlargement of the cranial sutures, leading to the persistence of the bregmatic fontanelle, normally closed at 18 months. Note the disproportion between neurocranium and viscerocranium bones. b Rx A-P projection of abdomen and lower limbs. Femoral heads with loss of the normal spherical morphology and bilateral coxa vara were documented. Lateral subluxation of right tibio-talar joint was seen alongside subtalar dislocation. The first metatarsal bone was deviated medially. c Particular of panel b. d Rx A-P projection of the spine. Mild right convex thoracic scoliosis was evident
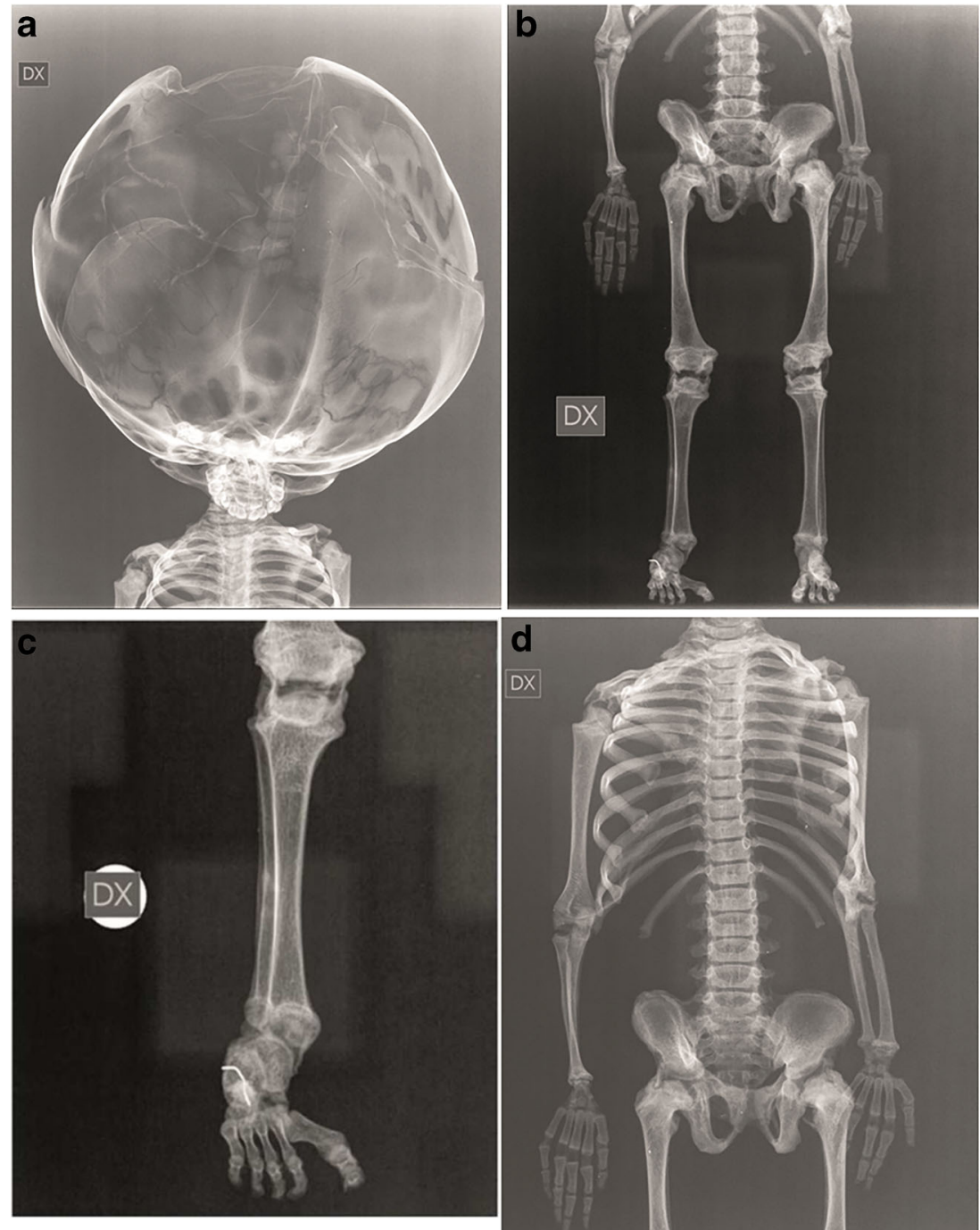

of these musealized objects. Wax models, employed in the past to instruct medical students in normal and pathological anatomy without resorting to corpse dissection, are admirable examples of symbiosis between art and science. They offered medical students hands-on experience of both normal and aberrant processes, which could not be gained with fixed organs and tissues [24].

Luigi Calamai, who moulded the hydrocephalic head, was a talented artist at the renowned anatomical wax studio $L a$ Specola, attached to the Imperiale e Regio Museo di Fisica e Storia Naturale established in 1775 under the patronage of the first Habsburg Grand Duke of Tuscany, Pietro Leopoldo (1747-1792) [16]. Calamai's outstanding botanical and anatomical waxes undoubtedly benefitted from his knowledge of chemistry applied to wax, along with an inborn skill for modelling and design [25].

There is no evidence to support any specific noxa in this historical case, although, based on the archival data, gross malformations of the neural tube, tumours and haemorrhage can all be excluded. Among the exogenous causes of congenital hydrocephalus, infectious agents, particularly Toxoplasma, Rubella virus and Cytomegalovirus, are potential aetiological factors, more feasible in this case than others, such as trauma, traces of which are visible neither on the skull nor on the post-cranial segments of the child's skeleton. In modern times, prevention and control of infectious diseases during pregnancy have dramatically decreased foetal/neonatal morbidity and mortality.

In our case, imaging studies showed massive enlargement of the skull vault, bulging of the fronto-parietal bones and enlargement of the middle cranial fossa, indicative of tetraventricular hydrocephalus. Radiographical alterations of the spine and lower limbs are likely to be related to abnormal gait. In the words of the German physician, Friedrich Dorner, discussing his medical thesis "De hydrocephalo chronico senili" (1826), the walking impairment of hydrocephalic patients (ataxia) was described as "hydrocephalici vacillant; atrophia cerebri laborantes recti incedunt" [Eng.: "hydrocephalic patients waver; although they 

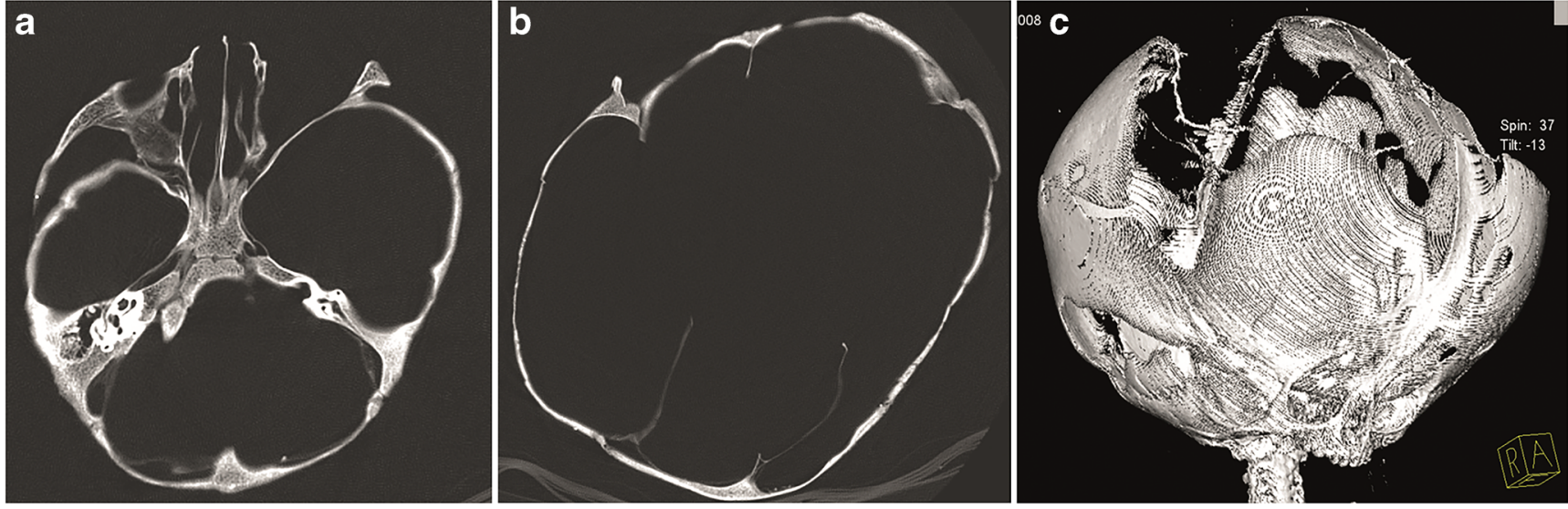

Fig. 4 a Axial CT of the skull. Skull base section showing remarkable enlargement of the posterior cranial fossa and asymmetric dilation of the middle cranial fossae. Thinning of the left lesser wing of the sphenoid, of the petrous portion of the left temporal bone and of the occipital bone was observed. b Axial CT of the skull. Middle third section of the skull

suffer in the brain, they (manage to) walk in upright posture" [26]]. An interesting aspect of the palaeo-radiological examination is that skeletal maturity and chronological age do not coincide, since the former is younger than the latter. The average of the skeletal ages obtained with different methods yields 10.5 months, which is less than the 18 months this hydrocephalic patient managed to survive. This discrepancy can, nonetheless, be explained mainly by means of a perturbation of the hormonal system (primarily the pituitary gland and its axis), an eventuality often encountered in similar neuro-developmental conditions [27].

Molecular testing on skeletal DNA also contributed to our results. Both population and molecular palaeopathology benefit from analysis of DNA isolated from ancient human remains and museum specimens (ancient DNA, aDNA).

a

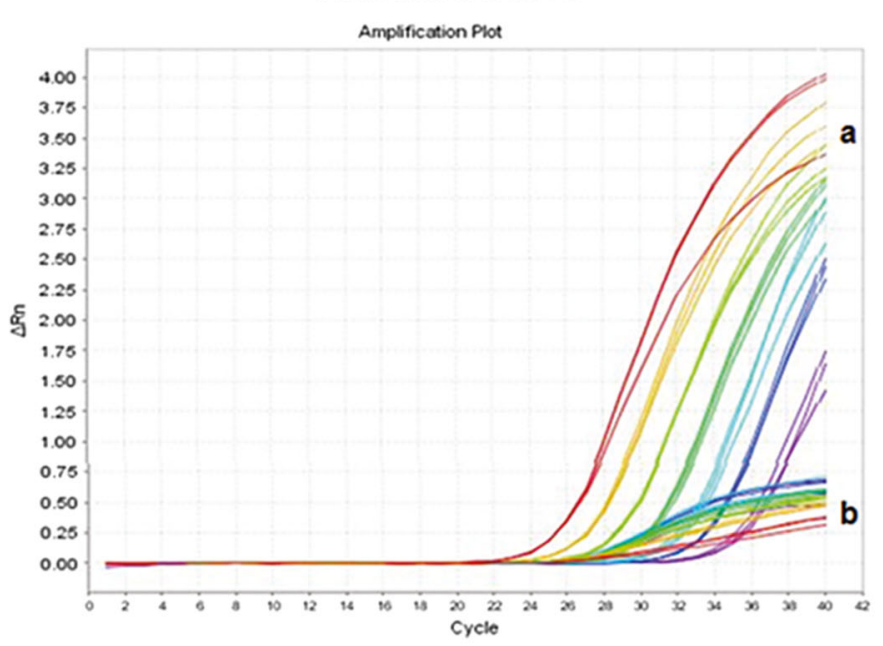

Fig. 5 a Standard curve obtained from quantification of DNA, extracted by a rib fragment, using real-time PCR technology. $a$, Human Quantifiler amplification plot; $b$, internal PCR control (ICP) amplification plot. b exhibiting irregular inner compact layer of the bones, due to compression of the cerebral cortex convolutions, from elevated intracranial pressure. c VRT 3D reconstruction of the skull, anterior view. Conspicuous enlargement of the skull with open sutures and persistence of the bregmatic and right mastoid fontanelles
However, problems in generating sufficient authentic DNA sequences can arise with aDNA which is not only scarce, and much fragmented, but also often chemically modified and contaminated by environmental DNA [28].

In our case, the copal varnish used to preserve the specimen could also have contributed to DNA alteration. Molecular analysis showed that the skeletal fragments, from which DNA was extracted, belonged to a male individual, thereby confirming the biological information in the original museum catalogue.

In conclusion, although the aetiology of this case of hydrocephalus could not be thoroughly elucidated, our multidisciplinary investigation, ranging from archival evidence to advanced palaeomolecular analyses, has made it possible to provide neurological research with the so-far most complete

\section{b Quantification of DNA from rib fragment}

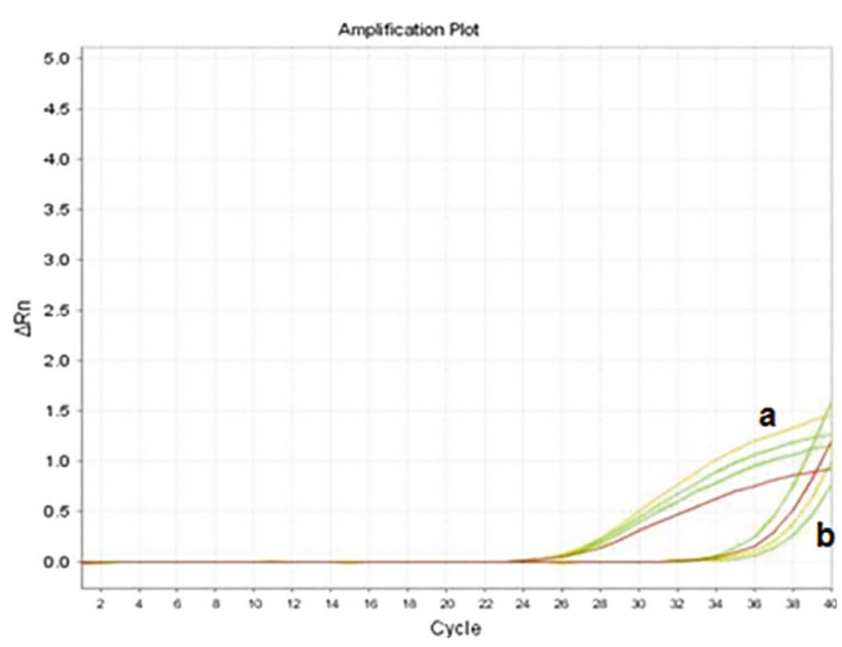

Quantification of DNA, extracted by a rib fragment, using real-time PCR. $a$, Human Quantifiler amplification plot; $b$, internal PCR control (ICP) amplification plot 


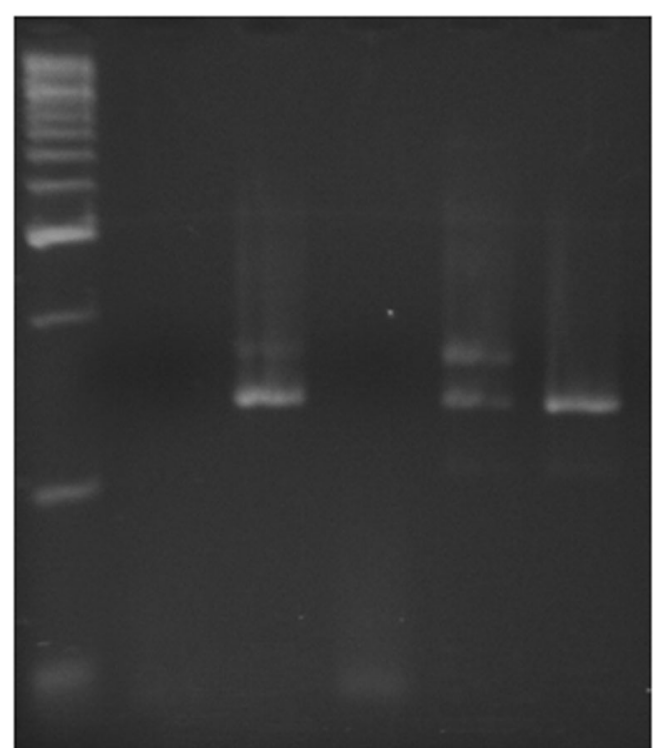

Fig. 6 Sex identification analysis. PCR product of DNA, visualized on ethidium-stained agarose gel, showed two fragments of $106 \mathrm{bp}$ (chromosome $\mathrm{X}$ ) and $112 \mathrm{bp}$ (chromosome $\mathrm{Y}$ ) matching the positive male control $(\mathrm{C}+$ male) electrophoretic profile

description of a severe case of hydrocephalus. Hydrocephalus can currently be diagnosed and treated thanks to the progress of medical knowledge and technology; yet, insufficient data are at hand regarding the evolutionary and historical trends of this pathology. Moreover, a relevant wax model, the most realistic type of representation of patient soft tissues before the introduction of scientific photography, allows a far higher degree of intimacy between observer and child, whose disability appears as though frozen in time - a snapshot from the past when medicine was still unable to effectively treat such devastating conditions. The feasibility of molecular studies on ancient specimens highlighted in our case does encourage further similar research projects in that vast treasure of knowledge represented by antique pathology collections.

Acknowledgements Thanks are due to the Fondazione Cassa di Risparmio di Firenze for their support of the Pathology Museum of the University of Florence. The authors wish to express their gratitude to Ugo Funaioli for his valuable work in ensuring housing and curation of the skeletal specimen collected. Francesco M. Galassi thanks the Mäxi Foundation (Zurich, Switzerland) for supporting his research.

\section{Compliance with ethical standards}

Conflict of interest The authors report that they have no financial interests or potential conflicts of interest.

\section{References}

1. Munch TN, Rostgaard K, Rasmussen ML, Wohlfahrt J, Juhler M, Melbye M (2012) Familial aggregation of congenital hydrocephalus in a nationwide cohort. Brain 135:2409-2415
2. Love S, Louis DN, Ellison DW (2008) Greenfield's neuropathology, 8th edn. Hodder Arnold, London

3. Aschoff A, Kremer P, Hashemi B, Kunze S (1999) The scientific history of hydrocephalus and its treatment. Neurosurg Rev 22: $67-93$

4. Lifshutz JI, Johnson WD (2001) History of hydrocephalus and its treatments. Neurosurg Focus 2001(11):1-5

5. Missori P, Paolini S, Currà A (2010) From congenital to idiopathic adult hydrocephalus: a historical research. Brain 133: 1836-1849

6. Aciduman A, Belen D (2009) Hydrocephalus and its treatment according to Rhazes. J Neurosurg Pediatr 3(3):161165

7. Turgut M (2009) Surgical scalpel used in the treatment of "infantile hydrocephalus" by Al Zahrawi (936-1013 ad). Childs Nerv Syst 25:1043-1044

8. Aufderheide AC, Rodríguez-Martín C (1998) The Cambridge encyclopedia of human paleopathology. Cambridge University Press, Cambridge, pp 57-58

9. Richards GD, Anton SC (1991) Craniofacial configuration and postcranial development of a hydrocephalic child (ca.2500 B.C.A.D. 500): with a review of cases and comment of diagnostic criteria. Am J Phys Anthropol 85:185-200

10. Eftekhar B, Dadmehr M, Ghodsi M, ParsaPour A, Ketabchi E (2007) Cranial trephination in ancient Iran, case illustration. J Neurosurg 106(1 Suppl):70

11. Rezaian J, Forouzanfar F (2012) Consideration on trephinated skull in the Åœahre-e Sukte (Burnt City) in Sistan. Res Hist Med 1(4): $157-168$

12. Zargaran A, Fazelzadeh A, Mohagheghzadeh A (2013) Surgeons and surgery from ancient Persia (5,000 years of surgical history). World J Surg 37(8):2002-2004

13. Castagna M, Giuffra V, Fattori S, Vitiello A, Caramella D, Giustini D, Fornaciari G (2014) Rickets at the Medici court of Florence: the case of don Filippino (1577-1582). Med Secoli 26(3):779-792

14. Fornaciari A, Giuffra V, Armocida E, Caramella D, Rühli FJ, Galassi FM (2018) Gout in Duke Federico of Montefeltro (14221482): a new pearl of the Italian Renaissance. Clin Exp Rheumatol $36: 15-20$

15. Habicht ME, Bianucci R, Buckley SA, Fletcher J, Bouwman AS, Öhrström LM, Seiler R, Galassi FM, Hajdas I, Vassilika E, Böni T, Henneberg M, Rühli FJ (2016) Queen Nefertari, the royal spouse of Pharaoh Ramses II: a multidisciplinary investigation of the mummified remains found in her tomb (QV66). PLoS One 11(11): e0166571

16. Nesi G, Santi R, Taddei GL (2009) Art and the teaching of pathological anatomy at the University of Florence since the nineteenth century. Virchows Arch 455:15-19

17. Galassi FM, Gelsi R (2015) Methodological limitations of an etiological framing of Ariarathes' goitre: response to Tekiner et al. J Endocrinol Investig 38(5):569-569

18. Ubelaker DH (1989) Human skeletal remains: excavation, analysis, interpretation. Taraxacum, Washington

19. Al Qahtani SJ (2008) Atlas of tooth development and eruption. Barts and the London School of Medicine and Dentistry. Queen Mary University of London. MClinDent, London

20. Maresh MM (1970) Measurements from roentgenograms. In: McCammon RW (ed) Human growth and development. C.C. Thomas, Springfield, pp 157-200

21. Greulich WW, Pyle SI (1950) Radiographic atlas of skeletal development of the hand and wrist. Stanford University Press, Stanford

22. Rohland N, Hofreiter M (2007) Ancient DNA extraction from bones and teeth. Nat Protoc 2:1756-1762 
23. Sullivan KM, Manucci A, Kimpton CP, Gill P (1993) A rapid and quantitative DNA sex test: fluorescence-based PCR analysis of XY homologous gene amelogenin. Biotechniques 15:636-641

24. Chen JCT, Amar AP, Levy ML, Apuzzo ML (1999) The development of anatomic art and sciences: the "ceroplastica" anatomic models of La Specola. Neurosurgery 45:883-891

25. Negri G (1932) Luigi Calamai, Ceraiolo e Naturalista fiorentino. "Atti Soc. Colombaria", Firenze
26. Dörner F (1826) De hydrocephalo chronico senili: dissertatio inauguralis. Becker, Würzburg 8

27. Feeley BT, Ip TC, Otsuka NY (2003) Skeletal maturity in myelomeningocele. J Pediatr Orthop 23:718-721

28. Willerslev E, Cooper A (2005) Ancient DNA. Proc Biol Sci 272:316 